\title{
TEATRALIDADES DE CALLE EN EL CUZCO COLONIAL"
}

\author{
STREET THEATRICALITY IN COLONIAL CUZCO
}

\section{MARÍA DELIA MARTÍNEZ N.**}

\section{RESUMEN}

La ciudad del Cuzco posee una importante actividad escénica de calle. En ella aún se puede identificar elementos que continuaron siendo parte de un sistema simbólico empleado para la representación escénica de un pasado mítico e histórico. Es el caso de las diferentes categorías del espacio idealizado en la ciudad del Cuzco y que se materializan por ejemplo a través de los ceques o líneas imaginarias que enlazaban lugares sagrados marcando referencias sociales y territoriales. El tiempo era a tal punto considerado una unidad con el espacio humanizado que las teatralidades se desarrollaron en medio de este contexto; las peregrinaciones, romerías y desfiles no sólo fueron recorridos sagrados sino que construyeron un espacio y un tiempo anudado en un tejido de sentido que alimentó un imaginario mítico y que aportó a la construcción identitaria de la región durante el periodo.

Palabras clave: Teatralidades, desfiles, espacio, colonial, andino.

\section{ABSTRACT}

In Cuzco, major theatrical performances take place in the street. Elements may still be identified of a system of symbols representing scenes of a mythical and historic past manifest, e.g., in various categories of idealized space in the city of Cuzco in the form of imaginary lines (ceques) linking sacred places and laying out social and

*Este artículo forma parte del proyecto FONDECYT 109.110 "Discursos coloniales, soportes, confluencias y transformaciones". Universidad de Chile.

** Académica Universidad Metropolitana de Ciencias de la Educación, UMCE. Estudiante Programa de Doctorado en Estudios Latinoamericanos. Facultad de Filosofía y Humanidades, Universidad de Chile. Santiago, Chile. Correo: deliacameliaster@gmail.com 
territorial references. Time was so intensely felt to be one with humanized space that performances took place in such a context; the routes followed by pilgrimages, processions, and parades were not only sacred but wove space and time into a tissue of feeling that fed a mythical imaginarium and helped to consolidate the identity of the region during the period.

Keywords: Performances, parades, space, colonial, andean.

Recibido: 20.03.11. Aceptado: 09.05.12.

\section{INTRODUCCIÓN}

$\mathrm{E}$ N JUNIO DE 1555, LAS CALLEJAS del Cuzco se prepararon para la celebración del Corpus Christi. Al capitán Garcilaso de la Vega le complacía la compañía de su hijo, el joven Gómez Suárez, de 15 años, quien se instaló con los suyos en la galería que dominaba la plaza principal. Pudo así ver arribar a los señores indígenas, los kurakas llegados de todos los alrededores, que avanzaban en filas con sus más bellos atuendos de antaño ${ }^{1}$. Desde los primeros años de la dominación española los desfiles formaron parte de la vida comunitaria en las grandes ciudades del virreinato. Los relatos históricos hacen referencia a las procesiones solemnes: con adornos en las calles, colgaduras y tapicerías en los balcones, y un numeroso acompañamiento. Los indígenas fueron activos participantes en los frecuentes desfiles y procesiones, en los que su incorporación era masiva.

Los espectáculos callejeros apelan a la calle como lugar de presencia y poder, y las teatralidades que la ocupan están asociadas al potencial de renovación, de encuentro y también de conflicto social. En este marco es la propia ciudad, o mejor, sus espacios públicos, donde se dará la lucha por establecer los significados de una teatralidad que extrapola la dimensión de la representación, pues supone el juego vivencial que se da como condición

1 “... traían todas las galas, ornamentos e invenciones que en tiempo de sus Reyes Incas usaban en la celebración de sus mayores fiestas; cada nación traía el blasón de su linaje, de donde se preciaba descender... Unos venían (como pintar a Hércules) vestidos con la piel del puma, sus cabezas encajadas en la del animal, porque se preciaban de descender de un león. Otros traían las alas de un ave muy grande que llaman kuntur, puestas a las espaldas, como las que pintan a los ángeles, porque se precian de descender de aquella ave. $Y$ así venían otros con otras divisas pintadas, como fuentes, lagos, sierras, montes, cuevas, porque decían que sus primeros padres salieron de aquellas cosas. Traían otras divisas extrañas, con los vestidos chapados de oro y plata. Otros con guirnaldas de oro y plata; otros venían hechos monstruos, con máscaras felinas... los indios de cada repartimiento pasaban con sus andas, con toda su parentela y acompañamiento, cantando cada provincia en su propia lengua... (Garcilaso de la Vega (1959 [1616], libro III, p. 123). 
básica del uso del espacio cotidiano. Considerando que la calle es funcionalmente un espacio de tránsito que permite una multiplicidad de relaciones, las que transforman cualitativamente el uso cotidiano de aquélla, se puede afirmar que el teatro que tiene como escenario la ciudad sugiere un diálogo que deforma ad infinitum esas nociones de acuerdo con las diferentes propuestas estéticas. Para los españoles del siglo XVI resultaba de importancia crucial fomentar el desarrollo del ceremonial público, puesto que se encontraban influidos por la Iglesia Contrarreformista europea, para la cual era fundamental fortalecer lo colectivo, expiatorio, y el culto a las imágenes ${ }^{2}$. En la década de los treinta se dictaron disposiciones para todo el Arzobispado de Toledo (Constituciones Sinodales de 1536), en las que se reconocía que las procesiones fueron instauradas y ordenadas para promover a los cristianos a devoción y porque "Nuestro Señor mejor oyere las oraciones y plegarias que en ellas se adjunta"; asimismo, en las bulas publicadas por Paulo III para la fundación de cofradías destinadas a rememorar la Pasión de Jesucristo, aquéllas quedaban obligadas a organizar desfiles procesionales la noche del Viernes Santo, con cruces, cirios y disciplinantes de sangre (González, 1993).

Desde el punto de vista político y militar, los desfiles se asentaron en la tradición romana relacionada con la fundación de ciudades y la conservación de las conquistadas. Este principio fundacional adquiere tradicionalmente un carácter histórico-teológico, ya que significa establecer un ámbito donde confluyen tiempos y generaciones, permitiendo la articulación de los actos humanos y la voluntad de los dioses (Benítez, 2001). Dicho principio permitió que los romanos pudieran garantizar la continuidad de los regímenes políticos y vincular este hecho con el destino humano, por encima de las circunstancias históricas ${ }^{3}$. Éstas se unen y se forman

\footnotetext{
${ }^{2}$ En España, antes de la celebración del concilio de Trento, ya se había dictado normas para el desarrollo de esas estrategias que, hacia finales del siglo XVI y principios del XVII, se tornaron generales, proyectando lo que luego se transformaría en los pasos procesionales de Semana Santa. De este modo, la Iglesia fortalece el concepto de sacralización del espacio, retomando tradiciones de origen judío como la de la peregrinación, estudiada y desarrollada teológicamente por Carlos Borromeo en Milán (siglo IV).

${ }^{3}$ Se puede encontrar mayor información al respecto en Disandro, Sentido politico de los romanos (1970). Asimismo, Virgilio, en La Eneida, desarrolla este punto mediante la figura de Eneas, paradigma del héroe fundador, que refleja la complejidad político-ética romana. El acto de fundar ciudades se ve como el destino político del hombre y, por otra parte, conservar las ciudades ya fundadas supone un constante acto creativo acorde con el destino político de la sociedad en la cual se inscribe. Ambos son actos espirituales, porque cada fundación y conservación significa la vinculación de los actos humanos con la voluntad divina. El destino universal del hombre es
} 
en el desfile, en cuanto demarcación de fronteras donde se conjugaba la expresión del poder y la voluntad de paz que, al reunir a vencidos y vencedores, simultáneamente incorporaba y dominaba a los miembros de una comunidad.

\section{TEATRALIDADES DE CALLE}

Tradicionalmente, el teatro de calle se estudia como un espectáculo relacionado con el deseo de producir un impacto socio-político directo, de tal forma que vincularía la interpretación cultural y las manifestaciones sociales (Pavis, 2000). Las imágenes urbanas funcionan como elementos que dan impulso a la construcción de secuencias de acciones dramáticas. Este procedimiento funciona bajo la lógica de operación del espacio que toma de las imágenes urbanas los elementos para la construcción espectacular, de tal forma que el diálogo con dichas estructuras constituiría el propio discurso del espectáculo. La noción de la ciudad como objeto cultural tiene un papel clave en la modulación de este enfoque (Pellettieri, 2008). Es posible tomarla como un discurso, una narrativa que define los elementos en juego, ya que las teatralidades callejeras serían entonces una nueva escritura de la ciudad ${ }^{4}$.

Las teatralidades en este contexto atestiguan el poder y lo configuran, contribuyendo con su despliegue a que se manifieste. En este caso, el juego de la mirada y la exposición, la ritualización del cuerpo, que marca zonas que se exhiben o se ocultan, que se realzan o se esconden para seducir, para diferenciarse o para poner distancias deben leerse a partir de complejas relaciones entre individuos y grupos en una situación colectiva excepcional. Esa excepcionalidad tiene a su vez momentos culminantes: el canto o baile colectivo, las luces y ornamentos, el silencio y el poder de la imagen presencial facilitan la disolución en la totalidad de un solo cuerpo mil veces más potente que sus partes (Turner, 1991).

El recorrido callejero determina el despliegue de las teatralidades por la

gobernar el mundo, al igual que los dioses rigen el universo; regir el mundo es configurarlo a nivel cultural y político de tal manera que la tierra salvaje sea civilizada y los hombres bárbaros acepten el principio fundacional.

${ }^{4}$ En la actualidad, el actor que invade la calle e incomoda al transeúnte está deformando las líneas que definen la ciudad y de esta manera exige que la mirada de aquél suponga una nueva escritura que sostiene el fenómeno espectacular. 
vía del espacio; este elemento es uno de los pilares del fenómeno teatral ${ }^{5}$. Cuando el espectáculo ocurre en un escenario, necesariamente debe tomar la forma de una semiología definida como un "espacio vacío" (Brook, 2000) que se ha de llenar en el interior de un marco fijo (espacio escenográfico tridimensional), marco susceptible de modificaciones escenográficas, pero fundamentalmente estable y limitado (Pavis, 2000). En el caso de los desfiles y teatralidades públicas, la determinación previa del espacio es un pie forzado existente por circunstancias que hablan de una historia, de una tradición y de una cotidianidad que actualiza el espacio. Si bien este espacio se encuentra previamente definido, desde el punto de vista de fondo que acoge el espectáculo, no ejerce la misma acción semántica que un escenario cerrado. Su valoración como relación y experiencia se torna teatralmente activa, puesto que el espacio como marco escénico está por definir. El espacio vacío no sólo hay que llenarlo, sino dibujarlo, señalarlo y determinarlo. Así el desfile, más que un lugar teatral o espacio escénico, se transforma en un espacio liminal, de frontera, que va a estar en permanente dialéctica con la representación que se lleva a cabo en él y con el significado que adquiera para el público que la presencia, puesto que la relación entre público y espectáculo apoya su construcción, lo delimita y lo restaura a medida que se desarrolla. Gracias a ello, el riesgo propio del teatro llega a su tensión máxima.

Uno de los pilares del fenómeno teatral de calle es crear una línea imaginaria que dibuja una frontera de integración/exclusión y de dominación de una comunidad, dado el peso que adquiere el espectáculo en relación con la restauración del poder en su configuración, así como el significado que este adquiere para el ámbito social, político y cultural. Es decir que las teatralidades callejeras constituyen un espacio liminal, donde no sólo se manifiesta una cierta estética teatral, sino también puede llegar a ser la radiografía de los poderes que se expresan en una comunidad (Portillo y Casado, 1992). Durante la Colonia, el recorrido teatral de procesiones y desfiles no sólo encarnaba el poder de autoridades específicas y auspiciaba el control sobre una comunidad, sino también reflejaba los propósitos de esa comunidad en tanto ejecutante y público, y señalaba un territorio con características geopolíticas, culturales e identitarias.

${ }^{5}$ La semiología del espacio y la práctica teatral que ella describe son muy conocidas, puesto que, desde el reconocimiento de la puesta en escena, reinan en la teoría y en la escena. Desde el naturalismo y el simbolismo hasta el realismo crítico brechtiano, el espacio está considerado como el marco de referencia en el interior del cual se inscriben la puesta en escena y el sentido. 
La inclusión de los desfiles y celebraciones, dentro de los márgenes de las denominadas teatralidades, se basa justamente en que la frontera entre teatro y fiesta, durante el Siglo de Oro, es imprecisa ${ }^{6}$, no sólo porque ambas manifestaciones necesitan la congregación de un público expectante, de una puesta en escena (que incluya espacio, decoración, iluminación, vestuario, música) de actores (profesionales o no) y de una acción condensada, sino también porque las celebraciones barrocas acogieron entre sus fastos representaciones teatrales en su forma plena; y al revés, porque lo escenificado en los tablados de los corrales y plazas fueron las jornadas de comedias y de autos, loas, entremeses, bailes; es decir, lo que muchos han denominado la fiesta teatral barroca, pero fundamentalmente porque los fastos contribuyeron al desarrollo de algunos géneros o subgéneros teatrales, como es el caso de la comedia cortesana.

\section{LAS TEATRALIDADES DEL CUZCO COLONIAL}

La sociedad colonial andina era muy compleja y, desde antes de la llegada de los españoles, muy heterogénea. La conquista, de cierta forma, logró una integración; sin embargo, añadió una nueva división a un mosaico de relaciones en que la tensión estaba latente. Luis Miguel Glave (2005) destaca el signo heterogéneo de la vida cotidiana y las relaciones entre los individuos y los grupos corporativos en los que las personas se integraban, puesto que no todos eran iguales ante las leyes, ni las leyes correspondían forzosamente a la realidad de la vida cotidiana. Los desfiles y procesiones se entienden como expresiones del poder político y religioso, respectivamente, admitiendo que esta separación no es sino una posible fórmula de relaciones, puesto que ambas manifestaciones mezclaban intereses de una y otra "república” (la llamada república de españoles y la república de indios). Por tanto, el estudio de desfiles y procesiones no puede realizarse sin aproximarse, al menos someramente, a las características que la sociedad colonial ofrece; en particular, sin señalar al menos las dificultades que surgen al intentar entender su riqueza y plasticidad.

\footnotetext{
${ }^{6}$ Sobre los límites entre teatro y fiesta en el Siglo de Oro, vid. J. M. Díez Borque, "Relaciones de teatro y fiesta en el Barroco español”, Teatro y fiesta en el Barroco. España e Iberoamérica, 1986, pp. 11-40; “Orbitas de teatralidad y géneros fronterizos en la dramaturgia del XVII", Criticón 42, 1988, pp. 103-124; Teoría, forma y función del teatro español de los siglos de oro, 1996.
} 
La sociedad colonial estaba dividida en partes separadas y excluyentes, que sin embargo se relacionaban entre sí e interactuaban cotidianamente. Se podría señalar, en términos muy generales, que debido al encuentro cotidiano de estas entidades con leyes propias, una extensa capa de mestizaje surgió como factor de cambio de la sociedad. Dado el carácter estamental y racista de la mentalidad colonial, las mezclas raciales se identificaban casi con obsesión, formando la escala social conocida como la de las "castas". No obstante, una sociedad regida por el honor, la piedad cristiana y el afán de lucro y de lujo siempre generaba comportamientos contradictorios que no se regían forzosamente por la rigidez de las castas.

La nueva manera de poblar que los españoles implantaron devino en la creación de ciudades peculiares, donde el entorno nativo marcó sus dinámicas e incluso influyó para convertir el espacio social en un escenario colectivo de creación, donde se gestaron nuevas identidades, conflictos y maneras de resolverlos. También fue un espacio de sentimientos y percepciones que conformaron mentalidades; regionales, étnicas, de género y nacional-criollas. Sin embargo, los desplazamientos y el trajín en un espacio definido por patrones precoloniales y coloniales aportaron a la creación de una cultura urbana determinada ${ }^{7}$.

La ciudad del Cuzco fue fundada en 1534 sobre las bases de la antigua capital de los Incas (Augurto, 2005, pp. 71-74). El plan español se sobrepuso a la ciudad inca y condicionó su desarrollo a ésta, en tres sectores: la ciudad nobiliaria, los arrabales cercanos al centro y los barrios satélites (Gutiérrez, 1981, pp. 11-23). Durante los primeros años de la conquista el Cuzco mantuvo preeminencia por sobre las otras ciudades del virreinato, sin embargo ya a fines del siglo XVI, aunque no era la cabecera del Perú, permitía el trayecto obligado de caravanas y comerciantes que viajaban entre Potosí y Lima. Por tanto, es permisible suponer que albergaba a gran número de personas en tránsito, que iban o venían de dichos centros urbanos, aunque mantuvo un aislamiento que pudo favorecer la persistencia de algunas cualidades prehispánicas.

\footnotetext{
${ }^{7}$ Luis Miguel Glave, en Trajinantes, caminos indígenas en la sociedad colonial (1989), desarrolla profusamente la importancia que adquiere la población de comerciantes, arrieros y temporeros que transitaban constantemente el espacio andino, convirtiéndose en una suerte de población flotante de importancia para el desarrollo de la vida social de las ciudades durante la Colonia.
} 


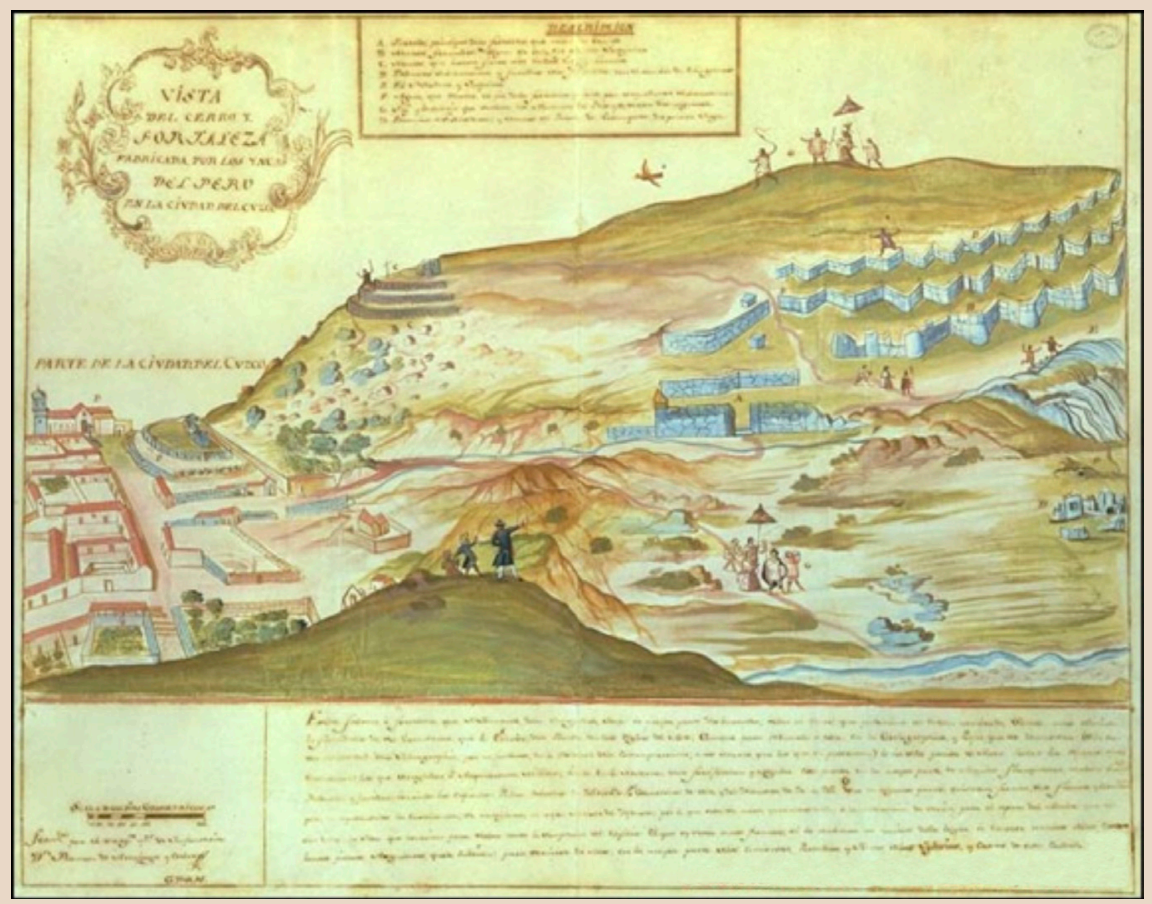

Sector de la ciudad de Cuzco al pie de las ruinas de Sacsahuamán. Sevilla. Archivo General de Indias MP, Perú y Chile, 220. Imagen extraída de http://www. mcu.es/archivos/CE/ExpoVisitVirtual/urbanismo_WAI/peru_imagen3.html

El patrón que aplicaron los españoles para la organización de las nuevas ciudades también se utilizó en el Cuzco, aunque con algunas variaciones, de acuerdo con la topografía de la zona. A inicios del periodo colonial se realizó la repartición de solares a los conquistadores españoles. La red vial estaba conformada por las calles reales y callejones que interconectaban los barrios al interior de las parroquias. Se siguió utilizando otros antiguos caminos incas, como los que se dirigían al Chinchaysuyo y Collasuyo, ubicados por el suroeste de la ciudad. Una red de ríos y riachuelos atravesaba la ciudad y, por tanto, fue necesaria la construcción de puentes que permitieran la circulación vehicular y peatonal. Los extramuros llegaban hasta la actual Plaza San Francisco y calle de Matara. El centro albergaba el equipamiento urbano como los conventos, monasterios, el Cabildo, la Casa de la Moneda. El espacio más importante era la Plaza de Armas, seguida de las plazas de San Francisco y Regocijo; a estos espacios de la ciudad seguían 
en importancia las plazuelas parroquiales (Esquivel y Navia, 1980, pp. 181182).

Con la llegada de los españoles, el centro nobiliario tomó el nombre de Parroquia Matriz. En 1559, el licenciado Polo de Ondegardo organizó a un número importante de indígenas, en siete pueblos, que se integraron a parroquias de indios, dividiendo la ciudad en un centro y una periferia. Luego, en 1570, el virrey Toledo, en su visita al Cuzco, formuló una serie de ordenanzas que confirmaron la ubicación de las parroquias de indios en las afueras de la ciudad; ésta, por el lado suroeste, desembocaba en la calle Matara, donde años más tarde se fundaría la parroquia de Hospital de Naturales. Progresivamente, se constituyeron las parroquias de Santa Ana, San Blas, Santiago, Belén, Hospital de Naturales, San Sebastián y San Jerónimo (Rubio, 1983, pp. 27-31). La construcción de estas parroquias quedó terminada en 1572; ellas abastecían de distintos productos (textiles, cerámica, utensilios) a los propietarios de las casas ubicadas en el centro, además de proporcionar personal para el servicio doméstico, mano de obra para edificación de casas y elaboración de detalles artesanales en madera y hierro.

La organización de dichos espacios facilitaba la evangelización, además de congregar a los kurakas al interior de parroquias de indios, lo que permitía mayor control sobre los ayllus reducidos (Esquivel y Navia, 1980, p. 26). Hacia el norte se asentaron ayllus de artesanos en San Blas y San Cristóbal, y se reubicaron algunos ayllus reales. Hacia el noreste, Santa Ana y Hospital de Naturales, se asentaron los ayllus dedicados a la agricultura, la que concentraba a una importante población flotante que venía a la ciudad para intercambiar productos. Hacia el suroeste, San Sebastián y San Jerónimo estaban dedicados a la agricultura. $\mathrm{Al}$ sur, las parroquias de Belén y Santiago, dedicadas a la agricultura y la alfarería. Este territorio coincide hoy con la ubicación de la estación de trenes de la ciudad y con dos mercados próximos a la iglesia de San Pedro. Hoy, las cofradías que representan a personajes como campesinos, productores y esclavos el día antes de la celebración de la Virgen de la Natividad, convergen en la Plaza de Armas desde esa zona.

La plaza, además de consolidar la centralidad de la ciudad, afirmó la preeminencia de las antiguas wacas y sitios ceremoniales que en la Colonia definieron renovados usos y significados. Mediante este proceso se reproducen los antiguos ejes, como el este-oeste, que se transforma en la vía sacra de la ciudad. Este eje es el que toman las cofradías de bailes el día 8 de septiembre, Día de la Virgen de la Natividad; parte desde la actual calle de Las Claras hacia la Iglesia de Santa Teresa por la calle Heladeros, que colinda 
con la Plaza del Regocijo, al final de la cual se encuentra el Convento de las Carmelitas Descalzas, donde se celebra una misa en la que participan las cofradías oficiales antes de enrumbar hacia Almudena.

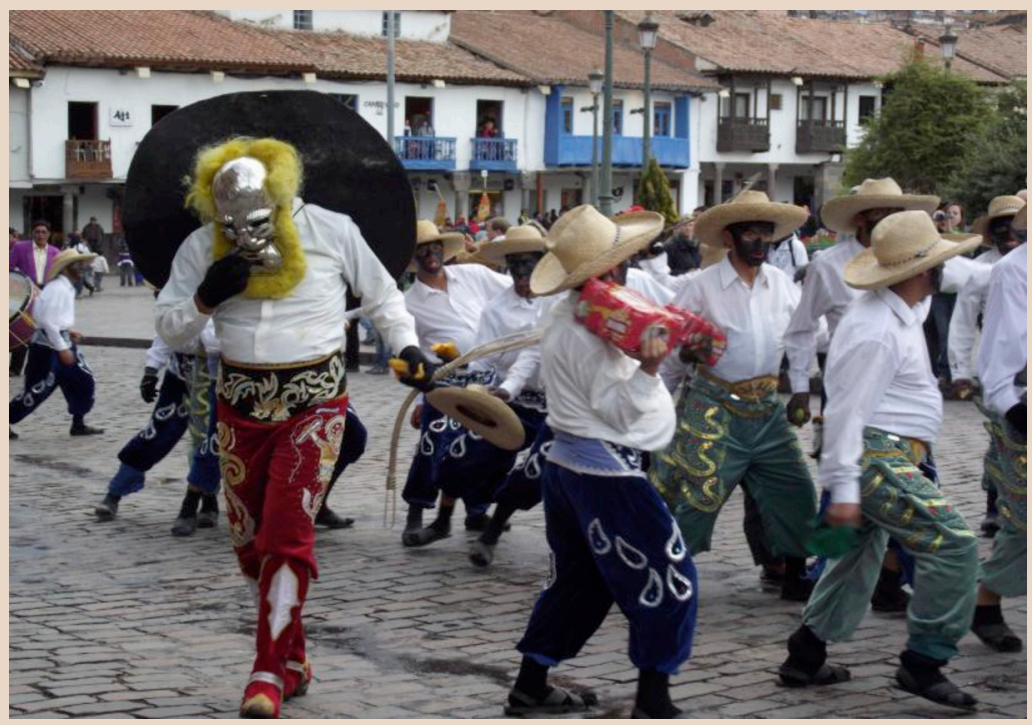

Celebración de la Virgen de la Natividad el 7 de septiembre de 2010.

Las escrituras públicas dan a conocer que había algunos barrios más apreciados, como el antiguo barrio de la nobleza incaica y las manzanas españolas que dividían las plazas de San Francisco y el Regocijo. Pero también en Matará o la Cruz Verde vivían indios y mestizos, a veces propietarios de casas. Además de que el colegio de San Borja, donde se educaban los hijos de kurakas, estaba a pocas cuadras de la catedral, hoy transformada en una galería comercial con el nombre de "La casa de las sierpes".

Como se señaló más arriba, la especificidad de los barrios estaba dada por la pertenencia a los antiguos ayllus. Las personas que vivían en las afueras de la ciudad se unían a las parroquias próximas al camino que conducía a su región de origen. En la zona de Cayacache, que se sumó a las tierras de la Orden de la Santísima Trinidad, los herederos del ayllu Usca Mayta, aún en el siglo XX, según Beyersdorff (2002), rememoraban los ritos de sus 
antepasados en torno de algunos adoratorios que quedaban en los senderos de la parroquia; lo anterior indica la persistencia de cierta toponimia sagrada, a pesar de la evangelización. Por esta misma razón, los caminantes de los senderos que pasaban cerca de los lugares de un antiguo culto transitaban por rutas irregulares, puesto que el trayecto se regía por la topografía cambiante del valle.

Este espacio idealizado y delimitado sirvió para la configuración de las teatralidades coloniales en esta ciudad. La grandeza de los desfiles exaltaba a los antiguos monarcas y magnificaba la imagen de los actuales, conjugando la gloria de la conquista y el poder del presente ${ }^{8}$. En el contexto del público que asistía a estas manifestaciones, cabe recordar que la ciudad era el lugar privilegiado de residencia de los europeos, mestizos y gente de color, y que los "pueblos" o "reducciones" eran habitación exclusiva de la población indígena.

Había corregidores de españoles y corregidores de indios, y cabildos igualmente diferenciados. Sin embargo, los kuracas aún mantenían mucho poder y este esquema obligaba a tomar contacto con las autoridades indígenas cuando se necesitaba la participación de esta comunidad en los desfiles y celebraciones públicas. Se sabe que desde temprano se solicitó a los indígenas que representaran a los Incas: en la tradicional descripción de la fiesta de Potosí, en 1555, un grupo "imita a los monarcas Incas en su corte, el cual iba compuesto de la nobleza indiana que en esta villa esistía" (Arzans y Vela, 1965: 215). Es el caso del cuadro que representa la fiesta del Corpus Cristi de mediados del siglo XVII, en que aparece el Alférez Real Inca de Su Majestad; se aprecia un personaje vestido con atuendo Inca9.

La integración de los kuracas a los desfiles implicaba la aceptación de un orden y de un poder al que se obedece y reconoce, pero no es fácil determi-

8 “... pudo Lima aventajar la imitación a la realidad, como dexar envidiosa la misma grandeza expressada en los romanos triumphos, si se observa la semejanza", señala la cita de un escritor anónimo recogida por Millones (1995) en su artículo sobre disfraces y desfiles. Anónimo, El Día de Lima. Proclamación real, que da el nombre augusto de el supremo señor don Fernando el VI, rey católico de las Españas y emperador de las Indias, hizo la muy noble y muy leal ciudad de los Reyes..., Lima, 1748, p. 251.

${ }^{9}$ Este cuadro, de autor anónimo, forma parte de una serie de quince, pintados probablemente a instancias del Obispo Mollinedo, varios de los cuales se encuentran en el Museo Arzobispal del Cuzco. En ellos es posible dimensionar el impacto cultural de los desfiles, en cuanto son motivo de diversas perspectivas plásticas plasmadas en estas imágenes, y observar una serie de elementos que dan consistencia a la importancia que adquieren las teatralidades en su relación con la escenificación, la jerarquía de las advocaciones allí representadas, la jerarquía social vinculada a ellas y su relación con la espacialidad en general. 
nar las condiciones de esta integración ni si en esa acción es posible reconocer la voluntad de recordar y de hacer recordar a una comunidad la propia historia. Al comienzo del periodo colonial, a los indígenas se les otorgó un lugar dentro de las celebraciones civiles y religiosas, y se les incentivó y obligó a participar con sus mejores trajes y representaciones, como señal de veneración del Dios católico.

\section{EL ESPACIO EN LA CIUDAD INCA DEL CUZCO}

Los complejos conceptos religiosos que fraccionaban las diferentes categorías del espacio y la sociedad incaica se idealizaban en líneas imaginarias denominadas ceques, que, saliendo del Templo del Sol, enlazaban los lugares sagrados, marcando referencias sociales y territoriales. Esos espacios se relacionaban con los ciclos del tiempo que dependían de los movimientos del Sol y la Luna y abarcabann varios hitos o sitios sagrados, descritos en las referencias coloniales como lugares donde se producía un cambio en el campo visual del caminante. "La décima (guaca) se llamaba Macaycalla; es un llano entre dos cerros, donde se pierde de vista lo que está destotraparte y se descubre la otra de adelante, y por sola esta razón lo adoraban" (Cobo, 1964: 176).

Para los incas el tiempo coincide con el espacio, como lo expresa inicialmente el vocablo quechua pacha que significa tiempo, suelo y lugar (González Holguín (1989 [1608]: 268). Esta sinonimia indica que el tiempo era considerado concretamente y proyectado sobre el espacio. También significa lo referente a la tierra, el mundo, el territorio o la época, las estaciones, etc. (Wachtel, 1971). La palabra pacha, precedida o seguida del término adecuado, puede dar lugar a la determinación de lugares, fases históricas o puede ser una expresión de temporalidad. El tiempo era a tal punto considerado una unidad con el espacio humanizado, que los ceques o líneas que partían del centro del mundo inca, la ciudad del Cuzco, no sólo permitían individualizar a grupos sociales y las 328 wacas que marcan el calendario ritual de 328 días de los Incas, sino que algunos de ellos codificaban también las observaciones astronómicas, indicando el punto de algunos momentos significativos del Sol y de la Luna (Zuidema, 1992).

En un estudio sobre el pensamiento mítico andino, Bouysse-Cassagne (1987) relaciona el concepto de pacha con el cielo, con el Sol y con el tiempo; pacha se refiere también a nociones espaciales y sociales. Si bien el tiempo se organiza en etapas sucesivas, representa también divisiones sociales que es- 
tán ligadas a un espacio en particular. Con la expansión incaica, Viracocha habría sido desplazado por Inti, el Sol, como principio ordenador y divinidad principal del estado cuzqueño, asociado al poder político y militar del Tawantinsuyu (Peace, 1978), aunque algunas investigaciones señalan una preeminencia del Sol, luego de la llegada de los españoles. El culto de los demás cuerpos celestes (Luna, estrellas, constelaciones y particularmente la Vía Láctea) mantuvo su notable importancia cultural y religiosa (Zuidema y Urton, 1976). Espacio y tiempo tienen un origen, un centro: Taypi, el "eje" cósmico, que puede llegar a estructurar la naturaleza que funciona en relación dialéctica con principios opuestos. El término Taypi, también puede llegar a asociarse con divinidades como Viracocha y, en relación con ella, los elementos y principios opuestos del cosmos se materializaban en los astros y las divinidades que los representaban (Bouysse-Cassagne, 1987). La profundidad del sentido del término, en la comprensión de un concepto que agrupe significados vinculados con el tiempo y con el espacio, abriría nuevas alternativas que, junto con definirlos, también amplían su alcance y su indeterminación, como en una muñeca rusa.

Si fuera posible abocarse sólo a la perspectiva espacial, aislándola del tiempo, en un interesante estudio acerca de los espacios fronterizos y cómo ellos se definen gracias a la presencia de elementos de la naturaleza ritualizados, Cecilia Sanhueza (2006) reconoce la construcción de fronteras sociales y políticas que se establecen recurriendo a determinados "instrumentos simbólicos". Estos “instrumentos simbólicos" se basaban en un particular concepto andino de "límite", en el que las divinidades constituían el material ideológico que lo sustentaba y los rituales eran su expresión concreta (Molinié-Fioravanti, 1986-87: 256). Por tanto, la noción de límite o frontera se construía a partir de categorías complejas que operaban en el ámbito de lo simbólico, pero que a su vez se expresaban y se materializaban en el paisaje andino mediante la selección de hitos, lugares o espacios a los que se otorgaba una significación particular (manantiales, cerros o altas cumbres, por ejemplo).

$\mathrm{Al}$ respecto resulta ilustrador el concepto de kaylla, sufijo asociado a la idea de orilla, borde, fin o cabo de algo, linderos y mojones (MoliniéFioravanti, 1986-87: 271), referidos a puntos de paso o transición entre un espacio y otro. La ubicación y distribución de las llamadas apachetas o acumulaciones rituales de piedras respondería también a este criterio y a una función demarcadora de espacios de cambio o transición, especialmente relacionada con la organización vial andina que articulaba espacios distintos (Molinié-Fioravanti, 1986: 87). Estos conceptos hablan de un tipo 
de atributo del espacio fronterizo cuya característica es la transición, como una etapa de ensamblaje entre dos partes, diferente del concepto occidental de límite como línea que se cruza para estar en otro lugar. Esta última conceptualización se puede entender como una abstracción formal que delimita linealmente los espacios sin contar con los tramos de transición o tránsito, de transformación necesaria para llegar a otro lugar.

Siguiendo en esta misma perspectiva, en relación con el tiempo de transición, puede aparecer, según Bouysse-Cassagne (1987), un periodo que permite la alternancia de contrarios en la voz Kuti, la que se puede entender como vuelta o cambio de turno, lo que se produce con una especie de armonía natural, como puede ser la llegada del solsticio que divide el año en dos (vilkakuti o vuelta del sol). En coincidencia con el espacio, también existe la noción de choque de contrarios en la voz tinku, aunque se mantiene la idea de la no exclusión de los contrarios, sino que su característica esencial radica en que son necesarias ambas partes para conseguir una unidad.

En cuanto a las teatralidades que surgen de los dos conceptos descritos, se podría llegar a identificar las batallas rituales que se practican aún, en ciertas zonas de los Andes, con la voz tinku, que refiere a encuentro entre cosas contrarias o cosas que provienen de direcciones opuestas, y a las teatralidades que surgen de los desfiles y los carnavales como yura, manifestación que se da, por ejemplo en los bailes de precosecha, que son otra representación del tránsito. En estos ritos se realizan danzas con productos enormes, de formas extrañas, llamados mamata y llallawa, "los cuales influirían en el tamaño de los productos que se va a cosechar" (Arce, 2007:9). En algunas zonas del norte de Chile, estas caracterizaciones se llevan a cabo a propósito de la festividad de San Isidro, patrón de los agricultores. Asimismo se puede observar que la llegada de las cofradías y grupos de danza a la plaza del Cuzco en la fiesta de la Natividad actualmente responde a un encuentro periódico, sin choque.

\section{EL ARCO IRIS, LOS COLORES Y EL SUPAY}

Ávila relata una romería en la que las personas que no habían participado en ella se reunían a esperar a los peregrinos, con el fin de saber cómo se hallaba el padre Pariacaca y, si la respuesta era favorable, bailaban durante cinco días. Muchas montañas en los Andes fueron objeto de culto por su carácter sagrado, fundamentalmente como oráculos que las hacía motivo de peregrinaciones y ofrendas. Por ejemplo, algunos portentos ocurrieron 
en Guacanacauri, cerro cercano al Cuzco. Según Joan de Santa Cruz Pachacuti (1993: 194, f.6 v.) en ese cerro vieron un arco iris, señal que auguraba a Manco Capac muchas victorias.

En el contexto de las teatralidades, una de las asociaciones posibles del arco iris es con el personaje de los supay, quienes usan trajes multicolores y están presentes en innumerables fiestas de la zona. El arco iris es un fenómeno complejo, pues se insinúa como una deidad plurisemántica, relacionada con las dos fuerzas que dominan el cosmos en la tradición cusqueña. Por un lado, el arco iris surge de las fauces de la madre tierra en ocasiones excepcionales $y$, por otro, es producto del agua que desciende sobre la tierra. Agua y tierra se reúnen gracias a un fenómeno como el arco iris que no es cíclico y se presenta sólo en ocasiones excepcionales, por tanto es imposible de augurar. En los textos coloniales, el arco iris es provocado por la potencia de supay, que lo levanta desde los manantiales, por cuya boca la Pachamama expulsa su fertilidad (De la Torre y Burga, 1994: 63). $\mathrm{Si}$ bien todas las formas de agua emergen o son paridas por las colinas, por los manantiales, por los caminos que surgen del inframundo y en consecuencia están relacionados con el Hurinpacha, tampoco se puede negar su gestación en el cielo. Entonces el arco iris sería la síntesis de la presencia del inframundo reunido con el cielo, en tanto que el agua se derrama sobre la Tierra y el Sol filtra sus rayos a través de ella y provoca este fenómeno cromático. El Arco Iris es un elemento que surge gracias a la ayuda del Sol $y$, en consecuencia, es una forma de manifestación tanto del inframundo como del mundo celestial. Posee cualidades de las regiones celestes, pero es principalmente acuático: "es percibido como una señal de que la entidad shapi intenta tomar, conquistar el cielo, pertenencia absoluta de la entidad Amito" (De la Torre y Burga, 1994).

Una cita de Bernabé Cobo permite suponer que los colores estaban unidos a los rumbos, por tanto, a una coordenada espacio-temporal: "ofrecíanle conchas de todos los colores, conforme a los tiempos" (Cobo, 1964: 175). Las ofrendas responden a una metodología determinada y su objeto es obtener resultados óptimos en un periodo preciso. El escrito hace pensar que las ofrendas de cierto color respondían a fechas puntuales del calendario ritual o que el espacio-tiempo se pensaba caracterizado por un color determinado.

El aspecto multicolor del arco iris y su relación con la fertilidad lo vincula con supay, ya que en el imaginario popular esta entidad se percibe de muchos colores y capaz de enfermar, pero también es portadora de lluvia; luego, en ciertas ocasiones, puede ser una fuerza que ayuda. El supay, cuan- 
do aparece en agosto, mes relacionado con el inframundo, se relaciona con la abundancia, la fertilidad y las lluvias que bañan las siembras (García, 2007). Pero, a la vez, se le teme, porque las lluvias que anuncia pueden regar en exceso los sembrados y "matar" la cosecha. Fray Martín de Murúa relaciona el arco iris del cielo, cuando asciende desde el Hurinpacha, con el supay que anuncia a los agricultores la regulación hidrológica ${ }^{10}$. En consecuencia, el arco iris pudo ser un agente controlador de la lluvia, formando un "circuito cerrado" por el cual circulaba el agua al comunicar los planos del cosmos. El arco iris del cielo se pudo ver como contenedor del agua, que -igual que la Vía Láctea en el texto de Dioses y hombres de Huarochir- evita desbordamientos. $\mathrm{Al}$ respecto, la investigadora Cecilia Sanhueza añade lo siguiente:

La variedad de colores era también un atributo de Mayu, asociado en algunas tradiciones con un río terrestre, el Pilcomayo de la región de frontera oriental del Tawantinsuyu. El Pilcomayo o río de la "mezcla de colores" cruzaba el espacio celeste "para hundirse en el ukhupacha, al oeste, y volver a ascender luego, henchido de tierra fértil (Zecenarro, 2001: 188, en Sanhueza, 2006: 68).

\footnotetext{
10 "Y vieron un Arco del Cielo, que era tiempo de aguas, y el un pie estaba fijado en el cerro [Huanacauri], y como lo viesen una mañana al alborear, de lejos, dijeron los unos a los otros : veis aquel Arco, y todos respondieron que sí, y dijo Manco Capac, el mayor: buena señal es aquella, que ya no se acabará el mundo por agua; vamos allá y desde allí veremos a donde hemos de fundar nuestro pueblo, y echaron suertes qué harían, y en ellas supieron cómo era buena llegar aquel cerro a ver lo que había y qué tierra se parecía de allí, y viniendo caminando hacia el cerro, de lejos vieron una huaca, bulto de persona, que estaba asentado, y el arco llegaba a los pies de la huaca. Era esta huaca de un poblezuelo llamado Sano, que estaba a una legua pequeña, de allí llámase huaca Chimpo y Cahua, y entraron en consulta y trataron que sería bueno cogerlo y que si no lo tomaban, que no tenían ningún remedio, y yendo a ello, Ayarcache, así como llegó a la huaca se asentó sobre ella y le dijo :¿qué hacéis, hermano? estemos juntos, y la huaca volvió la cabeza a conocer quién era, y como lo tenían oprimido, no lo pudo ver bien, y queriéndose desviar, no lo pudo, porque se le quedaron las plantas de los pies pegadas a las espaldas de la huaca. Los hermanos, entendiendo que ya estaba preso, fueron corriendo a ayudarle, y des que así se vio les dijo, cuando llegaron: mala obra me habéis hecho, que ya no puedo ir con vosotros; ya quedo apartado de vuestra compañía y sé que habéis de ser grandes señores. Lo que os ruego es que en todas vuestras fiestas y sacrificios os acordéis de mí y cuando hicieres Guarachico a vuestros hijos como a su padre que acá por todos queda, sea yo adorado dellos; y así quedó Ayarcache hecho piedra y le pusieron por nombre Guanacauri, y los hermanos, muy tristes, se volvieron la cuesta abajo y llegaron a un sitio que está a los pies del cerro Huanacauri, llamado Matahua, y allí horadaron las orejas a Sinchiroca, que es Huarachico, y lloraron la dejada de su hermano y dijeron: Oh, si nuestros hermanos vieran este infante, cómo se holgaran con él, y comenzaron a llorar, y allí se inventó el llanto de los muertos y las ceremonias con que se lloran, y tomando para ello el Pharasis y de las palomas, y allí inventaron las ceremonias de los raimis quico chico y rutu chico y la fiesta del ayuscai, que todo se declara en su lugar" (Murúa 2000: 41-42).
} 
El complejo sistema clasificatorio de los fenómenos naturales, en este caso, se relaciona con un espacio fronterizo que delimita, contiene y transforma. Delimita el espacio del Hurinpacha y del Hanacpacha mediante el cinturón de colores que es el arco iris; contiene las aguas, formando un circuito que permite que el agua transite por los espacios sacralizados del Hurinpacha y el Hanacpach;, y transforma su unión con el Sol en colores. Entonces no es sólo una formación bipolar, ya que en este caso las substancias se mezclan, se transforman, circulan y definen al mismo tiempo. Dada la consistencia que adquiere la metáfora del arco iris como cinturón, camino y límite, se puede asociar al papel que desempeñan los desfiles y procesiones en cuanto espacio liminal de la ciudad. Entendiendo el espacio liminal como un espacio de transición donde, si bien las autoridades religiosas y civiles intentan controlar el máximo de circunstancias, los distintos grupos sociales se encuentran en un escenario compartido donde se manifiestan, porque las teatralidades permiten una sobreposición de significantes imposible de controlar en todas sus variantes y porque el desfile mismo es plurisemántico y mantiene significados compartidos por todos, pero hay otros que son exclusivos de ciertos grupos de la sociedad colonial.

\section{CONCLUSIONES}

El desfile constituye un espacio público donde se puede plantear lo que De Certeau ${ }^{11}$ ha llamado "resistencia en adaptación", estrategia que combina aspectos formales, legales y políticos, como "tácticas" que se construyen como respuesta de la dominación. Los desfiles y procesiones constituyen un objeto de estudio en tanto son capaces de mostrar la confluencia de al menos tres grupos o sujetos sociales que actúan en él y se manifiestan. Uno de ellos es el grupo que auspicia el desfile, lo idea y configura; otro está formado por quienes lo realizan, definiendo estrategias formales de menor impacto, como peculiaridades de vestuario, despliegue corporal y gestual, etc. Otro grupo lo conforma el público o los destinatarios del desfile y, en rigor, en el caso de las manifestaciones religiosas, debiera incluir las divinidades afectadas como objeto de culto, que prodigan el favor o auguran aspectos del porvenir.

\footnotetext{
${ }^{11}$ Modelo de De Certeau, The Practice of Everyday Life (1984).
} 
Durante la Colonia, en la ciudad del Cuzco se presenta una primera etapa, en la que el poder eclesial y político impulsó a los indios a participar, con sus mejores galas, en los desfiles y procesiones de carácter religioso. La realización de dichos desfiles y procesiones abrió un espacio de expresión para las cofradías, donde se conjugó la acción de personas que podían tener distintos intereses en torno a su participación dentro del desfile. Con ayuda de algunas pinturas se puede ver cómo existía el apoyo de kurakas que vieron en la cofradía un lugar para legitimar su presencia y categoría dentro de la sociedad. Entre tanto, la población, que conformaba una suerte de público potencial, veía cómo se configuraba una comunidad cuyas características se desprendían del desempeño de los participantes y, posiblemente, de las cualidades significantes que era posible descifrar como parte de unas tradiciones antiguas, junto con nuevos elementos y formas de expresión provenientes de España. Asimismo, la ciudad como escenario abierto se transformó para dar lugar a un espacio de acción y manifestación potencial de intereses. El flujo del Cuzco estuvo determinado no sólo por el transito cotidiano de sus habitantes, sino también por el carácter de escenario eventual de sus calles, donde era posible manifestarse siguiendo las reglas impuestas por el poder eclesial y civil. Por tanto, el desfile constituía un eje de acción social.

Como frontera que delimita y contiene, se puede reconocer en estas manifestaciones coloniales la articulación de dos concepciones diferentes del espacio. Mientras en la tradición indígena la delimitación del espacio se asocia con la construcción de fronteras implementadas, ritualizadas, con la posibilidad de ser proyectadas, la noción occidental valora la definición lineal, lo meridiano, la exactitud que delimita sin transición y que fracciona. En el espacio teatral del desfile es posible encontrar un nexo entre estas dos concepciones, gracias al concepto de liminalidad que otorga contenido a un espacio que, si bien se dibuja, también se puede completar, en que se constituye una complementaridad mediante la suma de sus elementos, aunque también puede ser el escenario del choque y el conflicto, sin que ninguna de estas posibilidades se pueda descartar absolutamente como forma de ejercer la pertenencia a la ciudad.

En lo estético es liminal, puesto que los significantes se acumulan y entrelazan de manera impredecible y, en consecuencia, el riesgo propio de la acción teatral se multiplica. En el desfile, el cuerpo se constituye en un soporte estético que, representando a un personaje, lo sintetiza mediante acciones precisas y contundentes, dejando de lado el proceso dramático, pero manteniendo niveles de acción que permiten el interés de los espec- 
tadores. Estas caracterizaciones se suman mediante despliegues coreográficos colectivos, produciendo un personaje colectivo de impacto público, que "habla" o comunica haciendo uso de algunos elementos propios de la disciplina teatral. Por tanto, el desfile, en tanto espacio liminal estético, se crea fundamentalmente gracias al cuerpo y sus ornamentos. Si bien se trata de material dramático, productor de teatralidad o fuente de información y significación capaz de caracterizar a un personaje, el cuerpo, como soporte en este contexto, contribuye a rediseñar un espacio, alterando su cotidianidad, resignificándolo como territorio potencialmente creativo; apoyando su organización, además de remitir a otros sistemas de significantes, como los colores, los materiales, las máscaras, las coreografías, etc. Efectivamente, el desfile colonial va a diseñar una frontera o un límite de significación que determinará quiénes pertenecen o no al poder consolidado, pero sobre todo expresará en su contenido y hablará de la forma en que ese poder se aplica y se obedece. La confluencia de las concepciones que configuraron y dieron sentido al desfile hicieron de él un espacio propicio para la persistencia de tradiciones que se sostuvieron en gran medida sobre el potencial estético de las teatralidades.

\section{REFERENCIAS}

Anónimo (1748). El Día de Lima. Proclamación real, que da el nombre augusto de el supremo señor don Fernando el VI, rey católico de las Españas y emperador de las Indias, hizo la muy noble y muy leal ciudad de los Reyes... Lima.

Arce, R. (2007). "Tiempo y espacio en el Tawantinsuyu; Introducción a las concepciones espacio-temporales de los Incas". Nómadas. Revista Crítica de Ciencias Sociales y Jurídicas 16, 1-9.

Arriaga, P. (1968 [1621?]). Extirpación de la idolatría en el Perú. Madrid: Biblioteca de autores españoles, Atlas, T. CCIX.

Arzans de Orzúa y Vela, B. (1965 [1736]). Historia de la Villa Imperial de Potosí. Vol. 3. Providence, Rhode Island, U.S.A.: Brown University Press.

Augurto, S. (2005). Estudios acerca de la construcción, arquitectura y planeamiento Inca (pp. 71-74). Cámara Peruana de la Construcción -CAPECO-.

Benítez, L. (2001). "La misión de Roma, proyecto intemporal del mensaje". Facultad de Humanidades. Unne, Chaco, Buenos Aires. Disponible en: http:// www1.unne.edu.ar/cyt/2001/2-Humanisticas/H-004.pdf

Beyersdorff, M. (2002). "Caminos rituales y cartografía indígena: la vigencia de la Relación de las guacas del Cuzco de Bernabé Cobo en su época”. En: Fecoster, J. J. (Ed.), Incas e indios cristianos. Elites indígenas e identidades cristianas en los Andes Coloniales (pp. 39-59). Cusco: Centro de Estudios Regionales Andinos Bartolomé de Las Casas. IFEA. 
Bouysse-Cassagne, T. (1987). La identidad aymara. Aproximación histórica (siglo XV, siglo XVII). La Paz: HISBOL-IFEA.

Brook, P. (2000). El espacio vacío. Barcelona: Alba Editorial.

Cobo, B. ([1653] 1964). Historia del Nuevo Mundo. Biblioteca de Autores Españoles, Tomo XCII, vols. I y II. Madrid: Ediciones Atlas.

De Certeau, M. (1984). The Practice of Everydar Life. Berkeley: University of California.

De la Torre, C. y Burga, M. (1994). Andenes y camellones en el Perú andino: Historia, presente y futuro. Lima: Ministerio de la Presidencia - CONCYTEC, $379 \mathrm{pp}$.

Díez Borque, J. M. (1986). "Relaciones de teatro y fiesta en el Barroco español”. En: Diez Borque, J. M. (Comp.), Teatro y fiesta en el Barroco. España e Iberoamérica (pp. 11-40). Madrid: Ediciones del Serbal.

. (1988). "Órbitas de teatralidad y géneros fronterizos en la dramaturgia del XVII”. Criticón, 42, 103-124.

. (1996). Teoría, forma y función del teatro español de los siglos de oro. Barcelona: Oro Viejo.

Disandro, C.A. (1970). Sentido político de los romanos. Buenos Aires: Horizontes del Gral.

Esquivel y Navia, D. de (1980). Noticias cronológicas de la ciudad del Cusco. Lima: Fundación Wiese.

García I., C. (1906). Santo Toribio. Obra escrita con motivo del tercer centenario de la muerte del Santo arzobispo, Parte primera y segunda. Lima: Imprenta y libreria de San Pedro.

García, M. (2007). "El arco iris en la cosmovisión prehispánica centroandina”. Gazeta de Antropología, 23, 15-23. Disponible en: http://www.ugr. es/ pwlac/G23_15Carmen_Garcia_Escudero.html

Glave, L. M. (1989). Trajinantes, caminos indígenas en la sociedad colonial. Lima: Instituto de Apoyo Agrario.

. (2005). "Resistencia y adaptación en una sociedad colonial. El mundo andino peruano". Norba. Revista de Historia, 18, 51-64.

González Holguín, D. (1989 [1608]). Vocabulario de la lengua general de todo el Perú llamada lengua quechua o del Inca. Lima: Universidad Nacional Mayor de San Marcos.

González, M. (1993). "El arte procesional del barroco”. Cuadernos de Arte Español, 95. Madrid.

Gutiérrez, R. (1981). La Casa Cuzqueña. Resistencia: Universidad del Nor-Este de Argentina, pp. 11-23.

Millones, L. (1995). "Las ropas del Inca: Desfiles y disfraces indígenas coloniales”. Revista Crítica Literaria Latinoamericana 21 (41), 51-66.Molinié-Fioravanti, A. (1986-1987). "El simbolismo de frontera en los Andes". Revista del Museo Nacional, tomo XLVIII, 251-286.

Molinié- Fioravanti, A. (1986-1987). "El simbolismo de frontera en los Andes”. Revista del Museo Nacional, t. XLVIII, 251-286. 
Murúa, Fray Martín de (2000). Historia general del Perú. Col. Crónicas de Américas 25. Dastin: Madrid.

Pachacuti Yamqui Salcamaygua, Joan de Santa Cruz (1993[1613]). Relación de Antigüedad del Reyno del Perú. Lima: Instituto Francés de Estudios Andinos. Centro de Estudios Regionales Andinos, Bartolomé de las Casas.

Pavis, P. (2000). El análisis de los espectáculos. Barcelona: Paidós.

Peace, F. (1978). Del Tawantinsuyu a la historia del Perú. Lima: Instituto de Estudios Peruanos.

Pellettieri, O. (2008). Perspectivas teatrales. Buenos Aires: Galerna. Fundación Arlt.

Portillo y Casado, J. (1992). Abecedario del teatro. Sevilla: Alfacentro Andaluz de Teatro.

Rubio, M. (1983). Encuentro con el hombre andino. Grupo cultural Yuyachkani, Revista electrónica Tramoya, http://cdigital.uv.mx/bitstream/123456789 /3857/1/199025aP147.pdf

Sanhueza, C. (2006). "Espacio y tiempo en los límites del mundo. Los incas en el despoblado de Atacama”. Boletín del Museo Chileno de Arte Precolombino, 10(2), 51-77. Santiago de Chile. ISSN 0716-1530.

Turner, V. (1991). The Ritual Process; Structure and Anti-Structure. Ithaca (N.Y.): Cornell University Press.

Zuidema, T. \& Urton, G. (1976). "La constelación de la llama en los Andes peruanos". Allpanchis 9, 59-119. Cuzco.

Zuidema, T. (1992). El sistema de Ceques del Cuzco; La organización social de la capital de los Incas. Lima: Ed. Pontificia Universidad Católica del Perú, Fondo Editorial.

Wachtel, N. (1971). "Pensamiento salvaje y aculturación. El espacio y el tiempo en Felipe de Guaman Poma de Ayala y el Inca Garcilaso de la Vega. Sociedad e Ideologías". Ensayos de Historia y Antropología Andina. Lima: IEP. 